\title{
A Review for Urban Network Research
}

\author{
Jiping Sun, Langong Hou* \\ School of Civil Engineering and Architecture, Southwest University of Science and Technology, Mianyang, China \\ Email: ${ }^{*} 43243910 @ q q . c o m$
}

How to cite this paper: Sun, J. P., \& Hou, L. G. (2020). A Review for Urban Network Research. Open Journal of Social Sciences, $8,412-418$.

https://doi.org/10.4236/jss.2020.86031

Received: May 27, 2020

Accepted: June 21, 2020

Published: June 24, 2020

Copyright (c) 2020 by author(s) and Scientific Research Publishing Inc. This work is licensed under the Creative Commons Attribution International License (CC BY 4.0).

http://creativecommons.org/licenses/by/4.0/

\section{(c) (i) Open Acces}

\begin{abstract}
With the decline in transportation costs and the development of Internet technology, the functional connections between cities within the region have shifted from vertical hierarchical relationships to network connections. A study of city networks can provide a more detailed understanding of the interrelationships between cities. This article reviewed the research process of urban networks, classified and sorted out the existing urban network research in terms of research theories, and research method and contents, and pointed out the differences and problems in the existing domestic and foreign urban network research. Finally, the development trend of the research on the city network was prospected.
\end{abstract}

\section{Keywords}

Urban Network, China, Oversea

\section{Introduction}

The relationship between cities in the region is gradually changing from a vertical hierarchical relationship to a complex network relationship. The networked regional spatial structure is more conducive to regional development. Frequent exchanges between cities are conducive to the diffusion of economic factors and the growth of urban income. The study of urban networks can help planners to conceive the spatial structure of urban agglomerations and optimize suggestions for regional resource allocation and infrastructure construction. It can help planners to find new ways to improve the level of regional spatial layout. The review and analysis of urban network research can provide good support for subsequent urban network research. This article attempts to sort out the research of previous scholars to point out the existing problems in network research at this stage and find more suitable methods for urban network research.

The remainder of this article is organized in four sections. In Section 2, we re- 
viewed the research theories of urban networks. We then introduced the research method and content of the city network. In Section 4, we summarized and elaborated the literature, and predicted the future trend of urban network research.

\section{Research Theory: From Central Place Theory to Central Flow Theory, Attribute Network to Relational Network}

The proposal of the "central location" theory marked that the main body of urban geography research has shifted from a single city to an urban system. In the 1930s, Christaller conducted an experimental study on the market centers and service areas of rural settlements. Based on the ideal surface and the assumption of a rational economic man, he explained the geographic spatiality of human activities through the two concepts of central function and central place, and deduced the location standardization theory of the hexagonal market area, that is, the central place theory, one of the basic theories of clustering and urbanization. For a long period of time afterwards, urban geographers used the central theory to study the urban system. The central place theory emphasized the hierarchical relationship between cities. It is proposed that central places have hierarchical characteristics, and the higher the rank, the fewer the central places. Then Friedman (1986) proposed the world urban hypothesis and Sassen (2013) proposed that the control function of cities in the global economy became two basic theories of urban network research. Friedman believed that urban relations are hierarchical, so people can judge urban relations based on their economic strength. Sassen emphasized the need to study advanced producer services more specifically and these companies make some cities higher ranks than others. With the rapid development of the global economy and technology, the economic and information exchanges between cities are getting closer, and Godfrey and Zhou (1999) put forward "Don't underestimate the diversity and complexity of global interaction". The static scale relationship can no longer clearly reflect the relationship between cities, and the research direction of the regional spatial structure has begun to focus on the "flowing space" perspective based on dynamic correlation. Castells (1996) put forward the concepts of "information flow space", "flow space" and "network society". He divided social space into two types: flow space and field space, and proposed that society is composed of various flows, information, Capital, technology, human resources and other "factor flow" rely on flow space to connect with other cities in the region. Taylor (2009) also explored the misleading nature of the urban hierarchy in urban external relations, and proposed a centripetal center-centered model that began to foster a regional spatial association model from "local space" to a multicenter modeled in "flow space". The transformation of networked mode, at the same time, he believes that in order to describe the flow of space, it is necessary to select the appropriate "relational data". As a supplement to the "central location" theory, the "central flow" theory is about the center, location or flow, which can describe 
the external relationship of the city.

Domestic research on urban networks started later than abroad, and most of the theories draw on foreign scholars. In the 1980s, based on the existing foreign scholars' research theory and empirical research experience based on the actual situation of urban and rural development in China. Wan \& Liang (1986) and Ye (1987) analyzed the scale hierarchy of the Hubei urban system and the Gyeonggi urban system using scale-sequence theory. Later, with the rise of the concept of "urban network", the study of urban networking began to attract the attention of a large number of scholars. Jiang (1996) proposed that the performance of urban networking includes the internal network structure of the city, the external shape of the city, the network of urban groups, and the network of urban functions. This promoted the coordination and unification of the city's spatial network and functional network. Pan (2006) pointed out that the central city theory, urban network theory, and urban ecology theory were the three most important aspects of the theoretical innovation of urban development models in the process of contemporary China. Yao (2011) proposed that the development model of China's urban agglomeration modernization includes a highly concentrated, dual-core, appropriately decentralized, and transportation corridor axis development model.

\section{Research Method and Content: Gravity Model, Interlocking Model, Corporate Headquarters-Branch Method and Social Network Analysis Method}

In terms of research methods, Gravity model, interlocking model, corporate headquarters-branch method and social network analysis method are commonly used methods for studying urban network structure. The study of urban networks by foreign scholars originated from the study of corporate networks. Only a few scholars had paid attention to the study of urban networks before this century, and the research content was mainly concentrated on the urban system structure, dynamic mechanism and optimal regulation. Pierre-Henry Derrick believed that the shape of the corporate network depends on the shape of the urban system, and the two overlap with each other and are conditional on each other. After 2000, the research on urban networks has gradually increased, and it has become a hotspot of regional research in the past few years. The research on the external connections of cities in the network can be divided into two categories. The first category considered the spatial interaction between cities from the perspective of urban areas, economic activities and population, and evaluated them through enterprise association or social network analysis methods. Research by the World Urban Network (WCN) focused on producer services, mainly including finance, law, advertising, management consulting, etc. Other activities belong to the industrial sector but were knowledge-intensive, such as $\mathrm{R}$ $\& D$, insurance, accounting, engineering, etc. usually served large global companies. Taylor used the company's service value data to measure the degree of connection between cities in the city's global network through mathematical 
models (interlocking models). The POLYNET project team firstly used Taylor's interlocking network model to use the "high-end productive service industry" industry data to describe the interconnectivity between the cities in the eight major urban clusters in Northwest Europe and Europe. In the economic core areas of major cities, these areas formed a functional network in Northwest Europe. Although the geographical area of southeast England and Zurich was a single center, a functional network had been formed within the area. At the highest level, no significant functional association had been formed within the urban agglomeration. Mans (2014) also evaluated the connectivity of cities based on an interlocking model. The research perspective shifted from advanced producer services to urban networks that focused on specific industries (Indian renewable energy sector), and analyzed the status of Indian terminal cities. D. Radha (2017) used the service value data of a global service company distributed in 315 cities around the world to analyze the importance of node cities in the global city network using social network analysis (SNA), and found that New York and London provide more advanced Service and occupy a more important position. Another type of infrastructure system, including transportation and communication networks, reflected inter-city relationships. The topological characteristics of the transportation network could be used to study the spatial and functional economic processes occurring between cities. F. Bruinsma, Piet Rietveld (1992) used the gravity model to study the reachability of 42 major European cities in three infrastructure networks: highway, railway and aviation. Ben Derudder, Witlox F. (2008) used air passenger flow data to analyze the world city network.

Foreign scholars "exploration and empirical research on urban network theory provided a good basis for later scholars" research on urban network connections. Some scholars also pointed out that most of the research objects of the current world urban network research are concentrated in those areas that are critical to the global production network. The research on the network relationships of non-hub cities (small and medium-sized cities) and their interconnections with other cities are a trend in the study of world urban networks under the increasingly multipolar world economy.

Gravity model is a common method to measure the strength of interaction between cities. Yao, Ou (2009) used population size and GDP data to measure the strength of economic ties between cities in the Yangtze River Delta urban agglomeration through a gravity model. Yu et al. (2017) and Sun \& Luo (2016) quantitatively analyzed the urban economic agglomerations in Wuhan urban agglomeration and the Beijing-Tianjin-Hebei region using the modified gravity model. The interlocking model can be used to measure the degree of regional city association and functional polycentricity. Huang, Chen, Sellers, \& Xing (2017) selected passenger traffic data based on an interlocking model to study the network structure of the middle reaches of the Yangtze River. The corporate headquarters-branch method uses the connection between corporate headquarters and branches to characterize the association between cities. Tang \& Li 
(2014) used the enterprise association method to study and compare the urban systems in the Yangtze River Delta and the middle reaches of the Yangtze River. Li \& Zhou (2016) used the enterprise-headquarters branching method to measure the strength of interconnection between cities in the Yangtze River Delta network. Social network analysis is a research method for relational data, which provides a new way to study the characteristics of urban network structure and the position of nodes in the network. Fang \& Sun (2015) reconstructed the spatial structure of the Yangtze River Delta urban agglomeration based on intercity traffic data. Xia (2017) used Tencent's migration data to analyze the network density and node city centrality of the Beijing-Tianjin-Hebei urban agglomeration using social network analysis methods.

\section{Conclusion}

From the discussion above, the following conclusions and further discussions can be preliminarily obtained:

1) The studies of urban networks by foreign scholars were earlier than that in China, which provided the theoretical basis and empirical research experience for domestic scholars to carry out network research. Foreign scholars have studied the urban system from the urban hierarchical system to the urban network system, from "field space" to "flow space", from attribute-based data to relational-based data; the research results are quite rich; and the research scale is many. However, the development of domestic urban network research is relatively lagging behind. After the 1980s, relying on existing theoretical foundations of foreign countries for development research, the research scale was at the national and regional levels, focusing on the development of urban networks in the Yangtze River Delta, Pearl River Delta, Beijing, Tianjin and Hebei more complete area. On the whole, most of the domestic and foreign research objects of urban network research are economic centers of gravity, and the research of urban networks in regions with economic levels in the development stage needs to be strengthened.

2) In terms of research perspective, foreign scholars mostly started from the corporate network and infrastructure network, and focused more on the perspective of the corporate network to reflect the degree of association between cities based on global producer service relationship data. Compared with foreign countries, it is more difficult to obtain global enterprise relationship data, and it is also not suitable for domestic city network research. Domestic scholars mostly used inter-city transportation data, communication network data and other infrastructure relationship data to study and build city networks. With the development of information technology, the application of big data in the field of urban space research is increasing. It is easy to obtain social network relationship data such as Weibo check-in data, Baidu search data, and Tencent location big data. In recent years, urban network research results from the perspective of social cultural networks. A lot of output is coming, which is a new trend of future urban network research. 
3) In terms of research content, due to the relatively large research scale, foreign scholars have focused on the analysis of city levels and the degree of static association between cities. They lack of deep analysis and dynamic association of urban network structure. In addition to the study of the city hierarchy and the degree of inter-city connections, domestic scholars also analyzed the specific structural characteristics and spatial-temporal evolution characteristics of the urban network spatial pattern, urban network density, etc. The research content is more comprehensive.

4) The research scale of urban networks is mostly at the global and regional scale. Existing domestic research cases were mostly concentrated in the regional scale and economically developed areas such as the Yangtze River Delta, the Pearl River Delta, and Beijing-Tianjin-Hebei, where the urban system is relatively well-developed. The studies about developing areas are still insufficient. The research on the general city system also has the theoretical significance. The research results will help planners to rationally locate the special features of peripheral cities, determine the direction of urban development, improve the comprehensive transportation system within the region, and promote efficient division of labor and cooperation within urban clusters.

\section{Conflicts of Interest}

The authors declare no conflicts of interest regarding the publication of this paper.

\section{References}

Bruinsma, F., \& Rietveld, P. (1992). Urban Agglomerations in European Infrastructure Networks. Urban Studies, 30, 919-934. https://doi.org/10.1080/00420989320080861

Derudder, B., \& Witlox, F. (2008). Mapping World City Networks through Airline Flows: Context, Relevance, and Problems. Journal of Transport Geography, 16, 305-312. https://doi.org/10.1016/j.jtrangeo.2007.12.005

Fang, D. C., \& Sun, M. Y. (2015). Spatial Structure Reconstruction of Urban Agglomerations in the Yangtze River Delta in the Era of High-Speed Railway-Based on Social Network Analysis. Economic Geography, 35, 50-56.

Huang, J. N., Chen, S. Y., Sellers, J., \& Xing, X. J. (2017). Multi-Scale Network Structure Study of the Middle Reaches of the Yangtze River Urban Agglomeration Based on the Interlocking Model. Urban and Rural Planning, No. 5, 65-75.

Li, T., \& Zhou, R. (2016). Comparison of Correlation Measurement Methods for Network Hinterland Division in the Yangtze River Delta. Acta Geographica Sinica, 71, 236-250.

Mans, U. (2014). Understanding the Position of End Nodes in the World City Network: Using Peer City Analysis to Differentiate between Non-Hub Cities. Global Networks, 14, 188-209. https://doi.org/10.1111/glob.12016

Pan, Y. K. (2006). Theoretical Issues in China's Urban Development Model. Hebei Academic Journal, No. 6, 76-80.

Radha, D. (2017). A Social Network Analysis of World Cities Network. In 2nd IEEE International Conference on Computational Systems and Information Technology for Sustainable Solutions (p. 12). https://doi.org/10.1109/CSITSS.2017.8447571 
Sassen, S. (2013). The Global City: New York, London, Tokyo. Princeton, NJ: Princeton University Press.

Sun, J. W., \& Luo, B. Q. (2016). A Study on the Urban Structure and Economic Relations in the Beijing-Tianjin-Hebei Region. China Price, No. 9, 25-27 + 44 .

Tang, Z. L., \& Li, T. (2014). A Comparative Study of Urban Systems in the Beijing-Tianjin-Hebei, Yangtze River Delta, and Pearl River Delta Regions-Analytical Methods Based on Enterprise Association Networks. Shanghai Urban Planning, No. 6, 37-45.

Taylor, P. J. (2009). Urban Economics in Thrall to Christaller: A Misguided Search for City Hierarchies in External Urban Relations. Environment and Planning A, 41, 2550-2555. https://doi.org/10.1068/a42235

Wan, J. P., \& Liang, H. (1986). On the Characteristics and Development of the Urban System in Hubei Province. Journal of Hubei University (Philosophy and Social Sciences Edition), No. 1, 77-84.

Xia, Y. (2017). Analysis of the Network Structure of Urban Agglomerations Based on Tencent Migration Data: A Case Study of the Beijing-Tianjin-Hebei Urban Agglomeration. In China Urban Planning Society, Dongguan Municipal People's Government (Eds.), Rational Planning for Sustainable Development-2017 Chinese Urban Planning Proceedings of the Annual Meeting (16 Regional Planning and Urban Economy) (p. 9). Dongguan: China Urban Planning Society, Dongguan City People's Government.

Yao, S. M. (2011). The Characteristics of the Network Structure of the Modernization of Chinese Urban Agglomerations. In Science and Modernization Issue 4 (Total Issue 049) (p. 9). Beijing: China Modernization Research Center, Chinese Academy of Sciences.

Yao, Y., \& Ou, G. L. (2009). An Empirical Study of Urban Economic Connection Based on Transportation Improvement-Taking the Yangtze River Delta City Cluster as an Example. Transportation System Engineering and Information, 9, 156-160.

Ye, Y. M. (1987). A Brief Analysis of the Gyeonggi Urban System-Its Structure, Layout and Internal Connections. Urban Issues, No. 2, 21-28.

Yu, Y., Tong, Y., Hu, S. S., \& Ke, Y. Y. (2017). Measurement of Inter-City Interaction in Wuhan Urban Agglomeration. Urban Problems, No. 1, 44-52. 